\title{
Recurrent arch obstruction after repair of isolated coarctation of the aorta in neonates and young infants: Is low weight a risk factor?
}

\author{
Doff B. McElhinney, MDa \\ Song-Gui Yang, $\mathrm{MD}^{\mathrm{b}}$ \\ Alexa N. Hogarty, MD \\ Jack Rychik, MD ${ }^{\mathrm{b}}$ \\ Marie M. Gleason, $\mathrm{MD}^{\mathrm{b}}$ \\ Christopher H. Zachary, MDa \\ Jonathan J. Rome, $\mathrm{MD}^{\mathrm{b}}$ \\ Tom R. Karl, MDa \\ William M. DeCampli, MD, PhDa \\ Thomas L. Spray, MDa \\ J. William Gaynor, MDa
}

From the Divisions of Pediatric Cardiothoracic Surgery ${ }^{\mathrm{a}}$ and Pediatric Cardiology, ${ }^{\mathrm{b}}$ The Children's Hospital of Philadelphia and University of Pennsylvania School of Medicine, Philadelphia, $\mathrm{Pa}$

This study was supported in part by grants from The Daniel M. Tabas Endowed Chair in Cardiothoracic Surgery and The Ethel Brown Foerderer Fund for Excellence.

Presented in part at the 2000 Annual Meeting of the American Academy of Pediatrics, Chicago, Ill, October 28, 2000.

Received for publication Sept 22, 2000; revisions requested Dec 19, 2000; revisions received April 4, 2001; accepted for publication April 6, 2001.

Address for reprints: J. William Gaynor, MD, The Children's Hospital of Philadelphia, 34th St and Civic Center Blvd, Philadelphia, PA $19104 \quad$ (E-mail: gaynor@email.chop.edu).

J Thorac Cardiovasc Surg 2001;122:883-90

Copyright (C) 2001 by The American Association for Thoracic Surgery $0022-5223 / 2001 \$ 35.00+0 \quad \mathbf{1 2 / 1 / 1 1 6 3 1 6}$ doi: $10.1067 / \mathrm{mtc} .2001 .116316$
Background: Repair of aortic coarctation is often delayed in small infants because of the belief that such patients are at risk of recurrent arch obstruction and that growth will decrease this risk. To determine whether low weight was a risk factor for recurrent arch obstruction, we reviewed our experience with coarctation repair via left thoracotomy in infants less than 3 months of age.

Methods: From 1990 to 1999, 103 patients less than 3 months of age underwent repair of aortic coarctation through a left thoracotomy. Median age was 18 days (1-90 days), with 45 patients less than 2 weeks. Median weight was $3.3 \mathrm{~kg}$ (1.0$6.4 \mathrm{~kg}$ ) and 14 patients were less than $2 \mathrm{~kg}$. The method of repair was resection and end-to-end anastomosis in 64 patients, subclavian flap angioplasty in 34, and patch augmentation of the arch in 5. Demographic, echocardiographic, and operative variables were analyzed for correlation with recurrent arch obstruction.

Results: One early and 1 late death occurred, both in patients who had complications but no evidence of recoarctation. At median follow-up of 24 months, reinterventions for recurrent arch obstruction were performed in 15 patients. The median time to reintervention was 5 months and was less than 1 year in 12 patients. KaplanMeier freedom from arch reintervention was $88 \%$ at 1 year $(95 \%$ confidence intervals: $82 \%-94 \%$ ) and $82 \%$ at 5 years (95\% confidence intervals: $72 \%-92 \%)$. Factors associated with shorter duration to arch reintervention by univariable Cox regression included younger age (continuous, $P=.01$; $<2$ weeks, $P=.005$ ), smaller transverse arch (absolute diameter, $P<.001$; indexed to weight, $P=.03$; indexed to ascending aortic diameter, $P=.02$ ), and smaller ascending aorta (absolute diameter, $P=.02$ ). Smaller absolute transverse arch diameter and younger age were the only independent predictors of shorter time to arch reintervention by multivariable Cox regression analysis. Weight and type of repair did not correlate with risk of recoarctation.

Conclusions: Low weight is not a risk factor for recurrent obstruction after repair of coarctation of the aorta in infants less than 3 months of age. Rather, risk of recoarctation is more a function of the anatomy of the arch. Thus, it is not indicated to delay repair in low weight infants with the goal of achieving growth. 


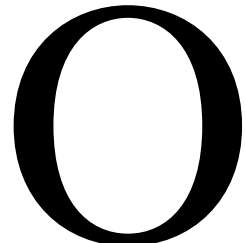

ne of the most common and important adverse outcomes in patients undergoing repair of aortic coarctation is recurrent arch obstruction. This is especially so in the current era, because mortality after repair of isolated coarctation is almost nonexistent in most large centers. ${ }^{1-13}$ Despite multiple studies focusing on the impact of technique of repair, few risk factors for recurrent obstruction have been identified. ${ }^{7-16}$ It is often thought that low weight neonates are at higher risk for adverse outcome, including recurrent obstruction. This belief may translate into a management approach aimed at avoiding early repair in these patients, with medical management being used until somatic growth allows for a more technically forgiving operative environment, with more mature aortic tissue and a larger patient. However, no evidence has been advanced to substantiate this approach. To address the relationship between low weight and recurrent arch obstruction, as well as to determine other factors that might correlate with recoarctation, we retrospectively studied 103 consecutive patients less than 3 months of age who had undergone repair of isolated aortic coarctation.

\section{Patients and Methods Patients}

From January 1990 through December 1999, 103 neonates and infants less than 3 months of age underwent primary repair of aortic coarctation through a left lateral thoracotomy. This does not include patients in this age range who underwent repair of aortic coarctation and associated anomalies through a median sternotomy. The group comprised 63 boys $(61 \%)$ and 40 girls. Twenty-five patients $(24 \%)$ were born prematurely ( $\leq 35$ weeks of estimated gestational age), and $41 \%$ of patients were transferred to our institution directly in the newborn period, before postpartum discharge home. Clear symptoms, including shock, feeding difficulties, or respiratory distress, were present in $59 \%$ of patients. The diagnosis was made in 30 of the remaining patients after detection of decreased pulses in the lower extremities with or without upper extremity hypertension, or during evaluation of a murmur or cyanotic episodes. In the 15 patients, some of whom were symptomatic at the time of presentation, the diagnosis was made on the basis of a fetal echocardiogram suggestive of aortic coarctation ( $n=7$; usually with small associated left heart structures) or on cardiovascular evaluation prompted by the existence of an associated genetic/malformation syndrome $(\mathrm{n}=8)$. An alprostadil (prostaglandin $\mathrm{E}_{1}$ ) infusion was administered and maintained until the time of repair in $40 \%$ of patients.

The median age at repair was 18 days (1-90 days). Repair was performed at less than 1 month of age in $66 \%$ of patients $(n=68)$, at less than 2 weeks in $44 \%(n=45)$, and at less than 1 week in $22 \%(\mathrm{n}=23)$. The median weight was $3.3 \mathrm{~kg}(1.0-6.4 \mathrm{~kg})$, with 14 (14\%) patients weighing less than $2 \mathrm{~kg}$ and $7(7 \%)$ less than $1.5 \mathrm{~kg}$. Associated cardiovascular anomalies and syndromes/noncardiovascular anomalies are summarized in Table 1 .

\section{Surgical Management}

All patients in this series underwent repair of aortic coarctation through a left posterolateral thoracotomy, with no additional procedures. Aortic clamping was used without cardiopulmonary bypass. The technique of repair varied according to era and the surgeon's preference. The majority of patients underwent repair with resection of the coarctation and end-to-end or extended end-to-end anastomosis $(n=64,62 \%)$, followed in frequency by subclavian flap angioplasty $(n=34,32 \%)$, end-to-end anastomosis with additional augmentation of the arch using a patch of allograft tissue ( $n$ $=3,3 \%)$, and patch aortoplasty $(n=2,2 \%)$.

\section{Echocardiographic Data}

Preoperative echocardiograms were reviewed for each patient for whom they were available $(\mathrm{n}=95)$. In the remaining 8 patients, preoperative echocardiography was not performed at our institution, and outside echocardiograms were not available for review at the time the study was conducted. From images obtained in the high-parasternal or suprasternal notch windows, diameters of the ascending aorta and aortic arch were measured off-line as described below and depicted in Figure 1. The diameter of the ascending aorta was measured immediately proximal to the origin of the first brachiocephalic vessel (innominate artery or common brachiocephalic trunk). The diameter of the transverse arch was measured between the left common carotid artery (or common brachiocephalic trunk) and left subclavian artery. The diameter of the aortic isthmus was measured at the site of the coarctation, or immediately proximal to the entrance of the arterial duct if patent. From a subcostal transverse image, the diameter of the descending aorta at the level of the diaphragm was also measured. These aortic diameters were indexed to the weight of the child at surgery. They were also indexed to one another, to give ratios of transverse arch to ascending aorta, isthmus to ascending aorta, and isthmus to transverse arch.

\section{Data Acquisition and Analysis}

Preoperative and operative data were collected retrospectively by reviewing patient records and the database of the Cardiac Center at The Children's Hospital of Philadelphia. Follow-up information was obtained by contacting the cardiologist and/or family of the patient, as approved by the Institutional Review Board for the Protection of Human Subjects. Follow-up echocardiographic, surgical, and catheterization-derived information was gathered from the patient records and databases at our institution, or from the referring cardiologist if the patient was followed up elsewhere.

Data are presented as mean \pm standard deviation or median (range), unless otherwise specified. The primary outcome measure was reintervention for recurrent obstruction of the arch. Secondary outcome measures were death and intervention for obstruction of the aortic valve and/or subvalvular left ventricular outflow tract. Independent variables assessed for correlation with these outcomes are listed in Table 2. Estimates of postoperative freedom from reintervention for recurrent arch obstruction, reinterventions on the valvular/subvalvular left ventricular outflow tract, and survival were obtained by the Kaplan-Meier product limit method and are expressed as the mean with $95 \%$ confidence intervals (CI). Univariable Cox proportional hazards regression was performed to assess for independent variables associated with shorter postoper- 
TABLE 1. Associated cardiovascular anomalies and genetic/congenital anomaly syndromes

\begin{tabular}{lc}
\hline Associated anomaly/syndrome & No. (\%) of patients \\
\hline Associated cardiovascular anomalies & $89(86 \%)$ \\
Bileaflet aortic valve & $83(81 \%)$ \\
Small ventricular septal defect & $19(18 \%)$ \\
Left-sided superior caval vein to the coronary sinus & $15(15 \%)$ \\
Valvular aortic stenosis* & $7(7 \%)$ \\
Structural/functional anomalies of mitral valve complex† & $7(7 \%)$ \\
Common brachiocephalic trunk & $5(5 \%)$ \\
Atrioventricular septal defectł & $3(3 \%)$ \\
Sinus venosus atrial septal defect & $2(2 \%)$ \\
Coronary sinus septal defect & $1(1 \%)$ \\
Associated genetic/congenital anomaly syndromes & $14(14 \%)$ \\
Turner syndrome & $6(6 \%)$ \\
Smith-Lemli-Optiz syndrome & $1(1 \%)$ \\
VACTERL association & $1(1 \%)$ \\
CHARGE association & $1(1 \%)$ \\
Trisomy 21 & $1(1 \%)$ \\
Chromosome 15q deletion & $1(1 \%)$ \\
Partial chromosome 4 duplication & $1(1 \%)$ \\
Multiple noncardiac anomalies without identifiable syndrome & $2(2 \%)$
\end{tabular}

VACTERL, Vertebral anomalies, anal atresia, cardiac abnormalities, tracheoesophageal fistula or esophageal atresia, renal agenesis and dysplasia, and limb defects; CHARGE, coloboma, heart disease, atresia choanae, retarded growth and development and/or central nervous system anomalies, genital hypoplasia, and ear anomalies and/or deafness.

*One patient had undergone prior balloon aortic valvuloplasty.

tNot including small valve size, decreased interpapillary distance, or common atrioventricular valve. Mitral valve anomalies included mild stenosis in 2 patients, moderate regurgitation in 2, double-orifice valve in 1, parachute valve in 1, and chordal attachments to the interventricular septum in 1.

$\ddagger$ Complete, transitional, and partial atrioventricular septal defect in 1 patient each.

ative freedom from arch reinterventions, shorter postoperative freedom from other reinterventions, and decreased postoperative survival. Factors found to be significant by univariable analysis, with a $P$ value $\leq .05$, were entered into multivariable Cox regression analysis. On the basis of a recent study in which patients with a surgical weight of less than $1.5 \mathrm{~kg}$ were found to have a significantly shorter freedom from reintervention for recurrent arch obstruction than patients between 1.5 and $2.0 \mathrm{~kg}$ at the time of surgery, ${ }^{16}$ we also assessed outcomes, as described above, among the cohort of patients weighing less than $2.0 \mathrm{~kg}$. Results of Cox regression analysis are presented in terms of odds ratio (OR) with 95\% confidence intervals. Linear regression analysis was used to test for correlation between continuous variables. SPSS for Windows version 7.0 (SPSS, Inc, Chicago, Ill) was used for statistical analysis.

\section{Results}

\section{Demographic and Morphometric Associations}

Age at repair, weight at repair, and technique of repair did not differ significantly between the earlier and later parts of our experience. No correlation existed between age and weight at repair. Patients who were admitted directly as neonates were significantly younger at the time of surgery than those who were not $(14.2 \pm 18.5$ vs $38.2 \pm 25.7$ days; $P<.001)$, and patients who were maintained on an alprostadil infusion were significantly younger at the time of surgery than those who were not $(10.6 \pm 12.6$ vs $39.8 \pm$ 25.6 days; $P<.001$ ). Premature infants underwent repair at a significantly older age $(37 \pm 29$ vs $26 \pm 24$ days; $P=.05)$ and lower weight $(2.2 \pm 0.9$ vs $3.7 \pm 0.9 \mathrm{~kg} ; P<.001)$ than term neonates. By linear regression, age as a continuous variable correlated with the absolute diameter of the ascending aorta $(r=0.34, P=.001)$ and the absolute diameter of the transverse $\operatorname{arch}(r=0.39, P<.001)$. Weight as a continuous variable correlated with the absolute diameter of the ascending aorta $(r=0.33, P=.002)$, the absolute diameter of the transverse $\operatorname{arch}(r=0.47, P<.001)$, and the diameter of the transverse arch indexed to weight $(r=0.76, P<.001)$.

\section{Survival}

Cross-sectional follow-up data were available in all patients and ranged from 5 months to 9.3 years (median 24 months) after repair. Follow-up of at least 6 months was available on all surviving patients, and all but $11(\mathrm{n}=90,89 \%)$ were followed up for at least 1 year. There were 2 deaths during the study period, both in low weight infants. There was 1 early death in a patient born weighing $718 \mathrm{~g}$ at 28 weeks' gestation, after a pregnancy complicated by twin-twin transfusion in which the patient was the donor twin. The postnatal course was complicated by necrotizing enterocolitis, and the patient underwent coarctation repair at an age of 66 days 


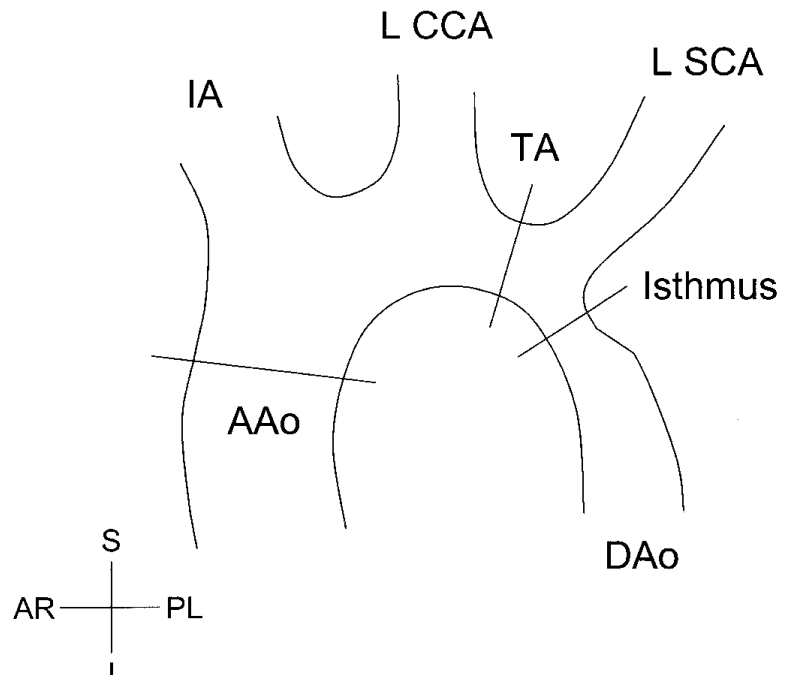

Figure 1. Diagram depicting the sites on the high parasternal echocardiographic image at which the diameters of the ascending aorta $(A A o)$, transverse arch $(T A)$, and isthmus were measured. Also labeled are the left (L) common carotid (CCA) and subclavian (SCA) arteries, the innominate artery (IA), and the descending aorta (DAo). $A R$, Anterior and rightward; $I$, inferior; $P L$, posterior and leftward; $S$, superior.

and a weight of $1.5 \mathrm{~kg}$. After development of Escherichia coli sepsis, she had a cardiopulmonary arrest and could not be resuscitated. Echocardiographic examination before death demonstrated a patent aortic arch with no obstruction. The only other death occurred 5 months after repair in a premature infant (surgical weight $1.8 \mathrm{~kg}$ ) with multiple congenital anomalies who had progressive bilateral pulmonary vein stenosis ultimately necessitating support with extracorporeal membrane oxygenation. Catheterization in this patient revealed a widely patent arch with no transanastomotic gradient.

The Kaplan-Meier estimate of survival was $99 \%$ at 1 month (95\% CI: $97 \%-100 \%)$ and $98 \%$ at 1 year (95\% CI: 96\%-100\%) and beyond. By Cox regression analysis, none of the independent variables analyzed was associated with mortality.

\section{Reinterventions for Recurrent Arch Obstruction}

During the follow-up period, reinterventions for recurrent coarctation were performed in 15 patients. Reintervention was by transcatheter balloon arterioplasty in 14 patients and surgical patch aortoplasty in 1 . The median time to reintervention was 5 months (2-42 months) and was less than 6 months in $10(67 \%)$ patients, less than 1 year in $12(80 \%)$, and less than 2 years in 14 (93\%). At the time of reintervention, the median gradient across the obstruction measured during catheterization was $55 \mathrm{~mm} \mathrm{Hg}$ (25 to $100 \mathrm{~mm} \mathrm{Hg}$ ).
The recurrent obstruction was located at the isthmus only in 11 patients, at the isthmus and the distal arch in 3 , and at the level of the distal arch only in 1 . In 3 patients, the transverse arch was hypoplastic as well. The obstruction was discrete in 12 patients and over a long segment in 3. In all patients, the reintervention was successful, with postdilation/postoperative pressure gradients less than $20 \mathrm{~mm} \mathrm{Hg}$ and no need for subsequent arch interventions at a median follow-up of 27 months (8-106 months) after reintervention.

The Kaplan-Meier estimate of freedom from reintervention for recurrent arch obstruction was $90 \%$ at 6 months (95\% CI: $84 \%-96 \%$ ), $88 \%$ at 1 year (95\% CI: $82 \%-94 \%$ ), and $82 \%$ at 5 years (95\% CI: $72 \%-92 \%$ ) (Figure 2). Factors associated with shorter duration to recurrent coarctation by univariable Cox regression analysis are presented in Table 2. Notably, weight and prematurity did not correlate with risk of recurrent obstruction. Of the 15 patients who underwent reintervention, 12 were less than 2 weeks of age ( $80 \%$ vs $37 \%$ for patients not requiring reintervention; $P=.002$ ) and $11 \mathrm{had}$ a transverse arch diameter of $3.5 \mathrm{~mm}$ or less $(73 \% \mathrm{vs}$ $11 \%$ for patients not requiring reintervention; $P<.001)$ (Figure 2). A smaller transverse arch diameter (multivariable OR $=3.0[1.54-6.0] ; P=.001)$ and younger age at repair (multivariable $\mathrm{OR}=1.06$ [1.00-1.11]; $P=.05$ ) were the only independent predictors of shorter time to reintervention by multivariable Cox regression analysis.

Among the 14 patients weighing less than $2 \mathrm{~kg}$ at the time of repair, there was 1 early and 1 late death (described above), and only 1 patient underwent reintervention for recurrent arch obstruction. There were no significant differences in survival or freedom from reintervention for recurrent arch obstruction between patients weighing less than $1.5 \mathrm{~kg}$ and those weighing 1.5 to $2.0 \mathrm{~kg}$ at the time of repair.

\section{Other Reinterventions}

Six patients underwent reinterventions during the follow-up period for valvular and/or subvalvular systemic outflow tract obstruction, from 6 to 55 months after coarctation repair. Two of these patients had undergone prior balloon dilation for recurrent arch obstruction. Two patients had a Ross or Ross-Konno procedure, 1 with complex valvular and subvalvular obstruction and 1 with aortic regurgitation as well as valvular aortic stenosis; 2 underwent resection of subaortic stenosis, with gradients of 50 and $64 \mathrm{~mm} \mathrm{Hg}$; and 2 underwent transcatheter balloon valvuloplasty of the aortic valve for peak gradients of 74 and $96 \mathrm{~mm} \mathrm{Hg}$. All of these patients had a bileaflet aortic valve and 2 had evidence of valvular aortic stenosis before coarctation repair, 1 of whom had undergone balloon aortic valvuloplasty before the coarctation was repaired. Freedom from intervention on the valvular and/or subvalvular systemic outflow tract was $98 \%$ at 1 year (95\% CI: $95 \%-100 \%)$ and $88 \%$ at 5 years (95\% CI: $77 \%-99 \%$ ) after coarctation repair (Figure 3). 
TABLE 2. Results of univariable Cox regression analysis for factors associated with freedom from reintervention for recurrent arch obstruction

\begin{tabular}{|c|c|c|}
\hline Independent variable & OR $(95 \% \mathrm{Cl})^{*}$ & $P$ value \\
\hline \multicolumn{3}{|l|}{ Demographic variables } \\
\hline Age (continuous) & $1.08(1.02-1.14)$ & .01 \\
\hline Age $<2$ weeks & $6.3(1.77-22.4)$ & .005 \\
\hline Weight (continuous) & $1.19(0.74-1.82)$ & .48 \\
\hline Weight $<2 \mathrm{~kg}$ & $0.51(0.07-3.9)$ & .52 \\
\hline Premature birth & $0.22(0.03-1.70)$ & .15 \\
\hline Male sex & $1.15(0.41-3.3)$ & .79 \\
\hline \multicolumn{3}{|l|}{ Associated anomalies } \\
\hline Valvular aortic stenosis & $1.02(0.13-7.8)$ & .98 \\
\hline Bileaflet aortic valve & $2.2(0.29-17.4)$ & .44 \\
\hline Ventricular septal defect & $0.33(0.04-2.6)$ & .29 \\
\hline Abnormal mitral valve apparatus & $1.09(0.14-8.3)$ & .93 \\
\hline Left superior caval vein & $0.42(0.05-3.2)$ & .4 \\
\hline Common brachiocephalic trunk & $3.2(0.71-14.1)$ & .14 \\
\hline Syndromes/multiple noncardiac anomalies & $0.46(0.06-3.6)$ & .46 \\
\hline \multicolumn{3}{|l|}{ Morphometric variables } \\
\hline Ascending aorta diameter (absolute) & $2.1(1.14-3.8)$ & .02 \\
\hline Ascending aorta diameter indexed to weight & $1.34(0.74-2.4)$ & .48 \\
\hline Transverse arch diameter (absolute) & $3.8(2.0-7.4)$ & $<.001$ \\
\hline Transverse arch diameter indexed to weight & $7.9(2.0-31.4)$ & .04 \\
\hline Aortic isthmus diameter (absolute) & $1.37(0.80-2.3)$ & .32 \\
\hline Aortic isthmus diameter indexed to weight & $6.9(0.00-2600)$ & .65 \\
\hline Transverse arch/ascending aorta diameter ratio & $20.2(1.11-491)$ & .02 \\
\hline Isthmus/ascending aorta diameter ratio & $0.70(0.01-40.9)$ & .95 \\
\hline Isthmus/transverse arch diameter ratio & $6.2(0.01-4.1)$ & .28 \\
\hline \multicolumn{3}{|l|}{ Clinical/surgical variables } \\
\hline Symptoms of coarctation present $\dagger$ & $1.0(0.56-1.6)$ & .88 \\
\hline Diagnosis by fetal echocardiogram & $1.5(0.69-3.1)$ & .31 \\
\hline Newborn diagnosis and admission $\ddagger$ & $1.6(0.96-2.7)$ & .07 \\
\hline Alprostadil infusion§ & $1.7(0.98-2.8)$ & .06 \\
\hline Repair by subclavian flap angioplasty & $1.43(0.50-4.1)$ & .5 \\
\hline Repair by end-to-end anastomosis & $0.66(0.29-1.87)$ & .44 \\
\hline
\end{tabular}

${ }^{*} \mathrm{OR}$ (odds ratio) $>1$ indicates shorter freedom from reintervention.

tSymptoms including shock, respiratory distress, and/or feeding difficulties.

$\ddagger$ Without prior discharge to home.

$\S$ Alprostadil (prostaglandin $E_{1}$ ) infusion maintained until the time of coarctation repair.

None of the independent variables analyzed by Cox regression analysis was significantly associated with shorter time to valvular/subvalvular reintervention.

Six other patients underwent interventions subsequent to the coarctation repair for correction of atrioventricular septal defect $(n=3)$, sinus venosus atrial septal defect $(n=2)$, or ventricular septal defect $(n=1)$ between 4 and 21 months postoperatively. No mortality or significant morbidity was associated with any of the reinterventions.

\section{Discussion}

The primary objectives of this study were to determine whether low weight at the time of isolated coarctation repair was associated with a greater risk of recurrent arch obstruction and to identify other factors that correlated with likelihood of recurrent obstruction. We focused on the relationship between low weight and outcome because, as repair of congenital heart defects in the neonatal period has become more common for many lesions, repair in premature and small infants has become an increasingly important frontier. It has been suggested that premature and low weight infants are at increased risk of poor outcome after repair of congenital cardiovascular anomalies. Although the management of such infants may be more complex than with term neonates, early repair in premature and low weight patients with hemodynamically important heart dis- 

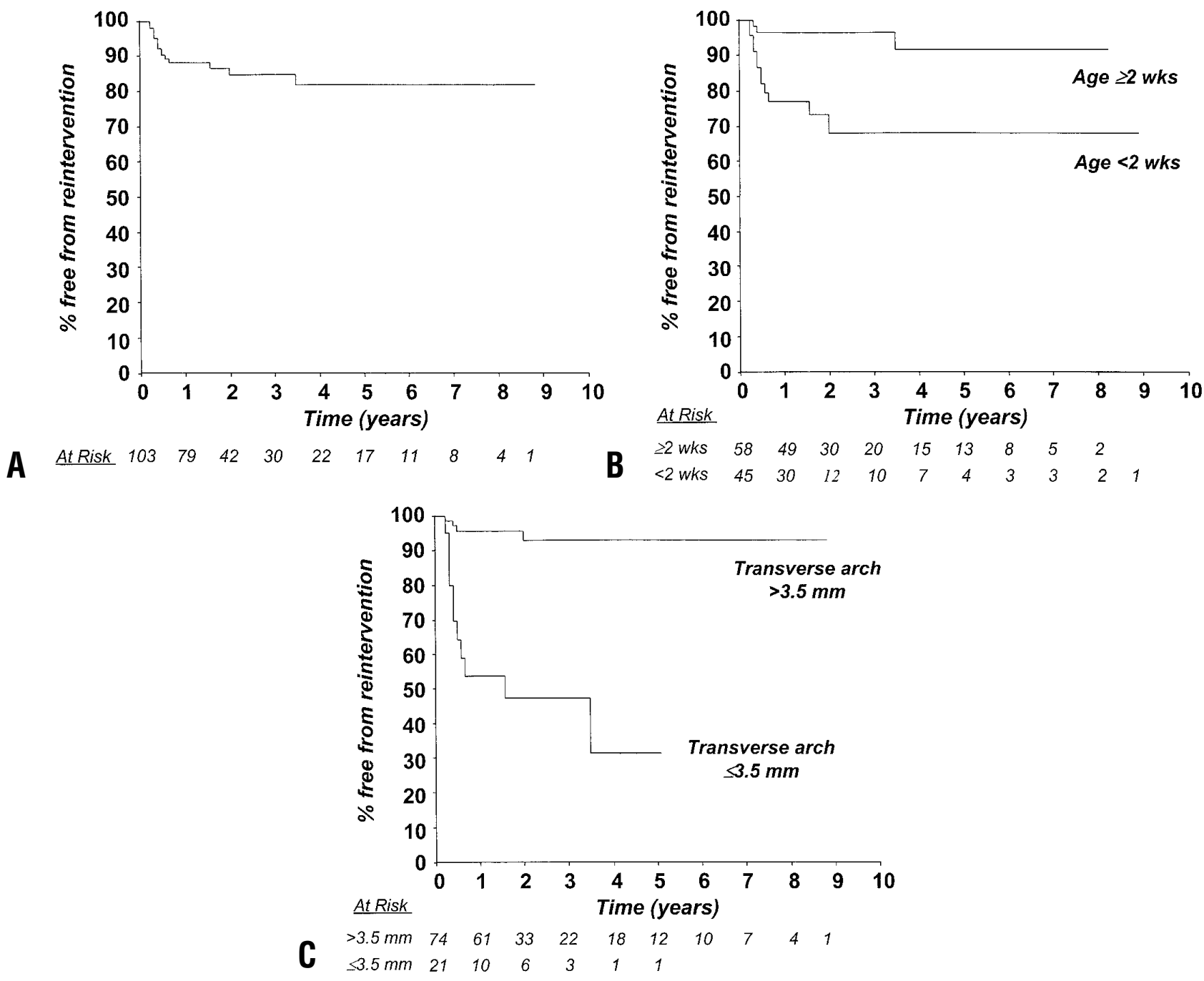

Figure 2. Kaplan-Meier curves for freedom from reintervention for recurrent arch obstruction. A, All patients; B, stratified according to age at repair; $\mathrm{C}$, stratified according to the diameter of the transverse arch (includes only the 95 patients with preoperative echocardiographic data available).

ease may be preferable to a more conservative approach aimed at medical management while waiting for the patient to grow. ${ }^{17}$ Among patients with hemodynamically significant heart disease, metabolic demand can be substantially elevated, and waiting for growth may not be an effective strategy. In a recent report from our institution, for example, low weight infants with hypoplastic left heart syndrome did not gain a significant amount of weight in the preoperative period. ${ }^{18}$

We could not demonstrate any correlation between recurrent arch obstruction and weight at the time of repair, analyzed as continuous variables and compacted into several dichotomous categories, or prematurity. Although weight did correlate with the preoperative diameter of the trans- verse arch, which was the strongest predictor of reintervention for recurrent arch obstruction, weight itself was not related to outcome. However, both of the deaths in our series occurred in premature infants, and although mortality was not related to surgery or recurrent arch obstruction, low weight and premature infants may still be at increased risk of poor outcome. Moreover, despite our preference for early repair even in low weight infants, premature infants in our series underwent repair at a significantly older age than term neonates and at a significantly lower weight, which suggests that repair was delayed on the basis of prematurity or small size in some of these patients.

In a recent review of 18 patients less than $2 \mathrm{~kg}$ undergoing repair of critical coarctation of the aorta, Bacha and 
associates $^{16}$ found weight less than $1.5 \mathrm{~kg}$ at the time of repair to be the only independent predictor of recurrent or residual arch obstruction. Eight of the 18 patients underwent reintervention for residual $(n=6)$ or recurrent $(n=2)$ arch obstruction, which differs markedly from our experience, in which reintervention was performed in 1 of 14 patients who weighed less than $2 \mathrm{~kg}$ at the time of the initial repair, with no statistically significant difference between patients weighing less than $1.5 \mathrm{~kg}$ and those weighing 1.5 to $2.0 \mathrm{~kg}$.

Mortality after repair of isolated coarctation of the aorta in neonates and young infants is minimal. In most recent series, as well as our experience, fewer than $2 \%$ of patients have died in the early postoperative period. ${ }^{1-13}$ As in other forms of congenital heart disease, the decreasing mortality associated with early repair of aortic coarctation brings other outcome measures into sharper focus. In patients undergoing early repair of coarctation, one of the most important and most common adverse outcomes is recurrent arch obstruction, which has been reported to occur in up to $30 \%$ of patients and is generally in the range of $10 \%$ to $20 \% .^{1-15}$

Despite the frequency and importance of recurrent arch obstruction, few risk factors for this complication have been identified. Fenchel and colleagues ${ }^{11}$ observed a higher probability of recurrent obstruction in patients undergoing repair with a continuous suture technique as opposed to interrupted, and a worse outcome in patients undergoing repair at less than 2 weeks of age. Similarly, Van Heurn, ${ }^{3}$ Sanchez, ${ }^{14}$ and their associates found younger age at repair to be a risk factor for recoarctation. $\mathrm{Wu}$ and colleagues ${ }^{15}$ found the size of the transverse arch to be associated with probability of recurrence. In these reports and most others investigating risk factors for recurrent arch obstruction after early coarctation repair, the primary focus has been the relationship between the technique of repair and recoarctation. On the whole, these studies demonstrate that the incidence of recurrent obstruction does not differ substantially between patients undergoing repair with subclavian flap angioplasty and resection with end-to-end anastomosis, although the probability of recoarctation appears to be higher after simple patch aortoplasty, and 1 study found a lower probability of recurrent obstruction in patients undergoing extended end-to-end repair. ${ }^{7-15}$ Otherwise, published data on risk factors for recoarctation are sparse.

In the present study, we found the diameter of the transverse arch and younger age at repair to be associated with shorter time to reintervention for recurrent arch obstruction by multivariable Cox regression analysis. Both of these risk factors have been reported by others. ${ }^{3,11,14,15}$ The diameter of the ascending aorta, the diameter of the transverse arch indexed to weight and to the diameter of the ascending aorta, and age less than 2 weeks were also significant by

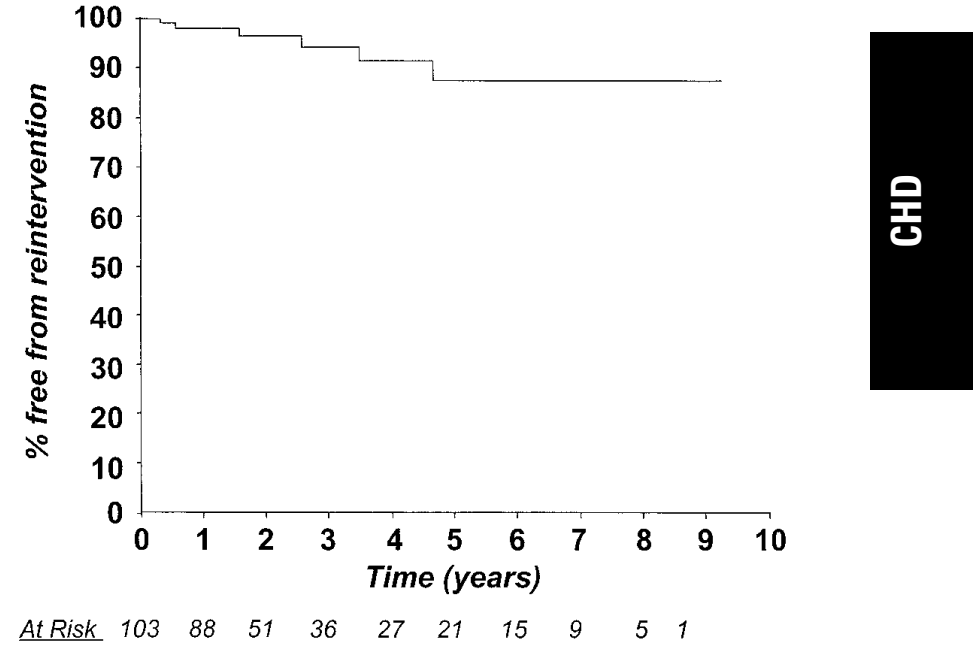

Figure 3. Kaplan-Meier curve for freedom from reinterventions for obstruction of the valvular/subvalvular left ventricular outflow tract.

univariable examination but not with multivariable analysis. Younger age at the time of repair correlated with smaller transverse arch diameter, but its association with recurrent coarctation was independent of this effect, as evidenced by the significance of both variables on multivariable Cox regression analysis. It is likely that age is at least in part a surrogate variable for severity of coarctation, inasmuch as there was a trend toward shorter freedom from reintervention in patients admitted directly to our center during the newborn period (ie, early diagnosis) and those in whom an alprostadil infusion was maintained until the time of surgery (ie, ductus-dependent). As with previous studies, we did not find any difference in the rate of recurrent arch obstruction according to the technique of repair.

Almost all of the interventions for recurrent coarctation in our series were performed within the first year after repair. Others have found this to be the case as well. ${ }^{13,19}$ The probable reason is that the rate of somatic growth is at its highest during the first year of life. However, it is not clear whether inadequate relief of the native obstruction or failure of arch growth in some patients simply becomes obvious during this period of rapid somatic growth or whether intrinsic abnormalities of the hypoplastic or surgically repaired arch interfere with normal growth. Although this issue deserves further study, it is important to note that none of the patients who underwent reintervention, which was by balloon dilation in all but 1 case, had subsequent recurrence of arch obstruction. Thus, it does not appear that there are intrinsic and persistent abnormalities of the arch that prevent growth of the arch altogether in patients who required a first arch reintervention. 


\section{Limitations of the Study}

The primary outcome that we assessed was reintervention for recurrent arch obstruction. One of the reasons that we elected to analyze this variable rather than recurrent obstruction per se is that some patients did not have echocardiographic examinations at their most recent followup. The presence of recurrent obstruction can be assessed by several methods, including blood pressure gradients between the upper and lower extremities by sphygmomanometry, peak instantaneous velocity across the arch by Doppler echocardiography, or peak-to-peak pressure gradient between the arch and descending aorta with cardiac catheterization. These techniques often yield substantially different estimates, and the determination of "significant" recurrent obstruction is somewhat arbitrary. Many clinicians and investigators use 20 to $25 \mathrm{~mm} \mathrm{Hg}$ as a threshold for qualifying recurrent obstruction as significant, and all of the patients who underwent reintervention in our study had at least this degree of obstruction. However, aside from potential hemodynamic and metabolic consequences of recurrent obstruction, reintervention is the most important variable that can be assessed with certainty. Thus, although using reintervention as the primary outcome measure may not be a completely accurate estimate of significant recoarctation, we do not believe that this limitation compromises the findings of our study.

Because we did not routinely assess the residual gradient across the anastomosis early after coarctation repair, we were not able to analyze this variable as a potential risk factor for reintervention. This may be an important limitation if the adequacy of the initial repair is a significant factor contributing to later need for arch reintervention. Only 5 of the patients who ultimately underwent arch reintervention had a discharge echocardiogram to assess the repair. Two of these had pressure gradients of more than $30 \mathrm{~mm} \mathrm{Hg}$, and gradients in the others were all less than $15 \mathrm{~mm} \mathrm{Hg}$.

As with most cross-sectional follow-up studies, the duration of follow-up varied extensively among our patients. Although Kaplan-Meier analysis accounts for the variability of follow-up duration for time-related outcomes, it is nevertheless possible that the incidence of outcome events may be underestimated. In anticipation of this consideration, we designed the study to allow for follow-up of at least 6 months postoperatively. Follow-up data of this duration were obtained for all survivors and for at least 1 year in $89 \%$. Two thirds of patients who underwent reinterventions had these procedures performed within 6 months of surgery and 80\% within 1 year. Thus, on the basis of our minimum follow-up duration of 6 months, a strong trend toward reinterventions within 1 year of surgery, and the statistical methods used, our analysis is unlikely to be dramatically skewed.

\section{References}

1. Quaegebeur JM, Jonas RA, Weinberg AD, Blackstone EH, Kirklin JW. Outcomes in seriously ill neonates with coarctation of the aorta: a multiinstitutional study. J Thorac Cardiovasc Surg. 1994;108:841-54.

2. Conte S, Lacour-Gayet F, Serraf A, Sousa-Uva M, Bruniaux J, Touchot A, et al. Surgical management of neonatal coarctation. $J$ Thorac Cardiovasc Surg. 1995;109:663-75.

3. van Heurn LW, Wong CM, Spiegelhalter DJ, Sorensen K, de Leval MR, Stark J, et al. Surgical treatment of aortic coarctation in infants younger than three months: 1985 to 1990 . Success of extended end-toend arch aortoplasty. J Thorac Cardiovasc Surg. 1994;107:74-86.

4. Zehr KJ, Gillinov AM, Redmond JM, Greene PS, Kan JS, Gardner TJ, et al. Repair of coarctation of the aorta in neonates and infants: a thirty-year experience. Ann Thorac Surg. 1995;59:33-41.

5. Kappetein AP, Zwinderman AH, Bogers AJ, Rohmer J, Huysmans H. More than thirty-five years of coarctation repair: an unexpected high relapse rate. J Thorac Cardiovasc Surg. 1994;107:87-95.

6. Merrill WH, Hoff SJ, Stewart JR, Elkins CC, Graham TP, Bender HW. Operative risk factors and durability of repair of coarctation of the aorta in the neonate. Ann Thorac Surg. 1994;58:399-403.

7. Rubay JE, Sluysman T, Alexandrescu V, Khelif K, Moulin D, Vliers A, et al. Surgical repair of coarctation of the aorta in infants under one year of age: long-term results in 146 patients comparing subclavian flap angioplasty and modified end-to-end anastomosis. J Cardiovasc Surg. 1992;33:216-22.

8. Beekman RH, Rocchini AP, Behrendt DM, Bove EL, Dick M, Crowley DC, et al. Long-term outcome after repair of coarctation in infancy: subclavian angioplasty does not reduce the need for reoperation. J Am Coll Cardiol. 1986;8:1406-11.

9. Cobanoglu A, Thyagarajan GK, Dobbs JL. Surgery for coarctation of the aorta in infants younger than 3 months: end-to-end repair versus subclavian flap angioplasty. Is either operation better? Eur $J$ Cardiothorac Surg. 1998;14:19-26.

10. Dietl CA, Torres AR, Favaloro RG, Fessler CL, Grunkemeier GL. Risk of recoarctation in neonates and infants after repair with patch aortoplasty, subclavian flap, and combined resection-flap procedure. $J$ Thorac Cardiovasc Surg. 1992;103:724-32.

11. Fenchel G, Steil E, Seybold-Epting W, Seboldt H, Apitz J, Hoffmeister HE. Repair of symptomatic aortic coarctation in the first three months of life: early and late results after resection and end-to-end anastomosis and subclavian flap angioplasty. J Cardiovasc Surg. 1988;29:25763.

12. Han MT, Hall DG, Mache A, Rittenhouse EA. Repair of neonatal aortic coarctation. J Pediatr Surg. 1995;30:709-12.

13. Knott-Craig CJ, Elkins RC, Ward KE, Overholt ED, Razook JD, McCue CA, et al. Neonatal coarctation repair: influence of technique on late results. Circulation. 1993;88(Suppl):II-198-204.

14. Sanchez GR, Balsara RK, Dunn JM, Mehta AV, O'Riordan AC. Recurrent obstruction after subclavian flap repair of coarctation of the aorta in infants: Can it be predicted or prevented? J Thorac Cardiovasc Surg. 1986;91:738-46.

15. Wu JL, Leung MP, Karlberg J, Chiu C, Lee J, Mok CK. Surgical repair of coarctation of the aorta in neonates: factors affecting early mortality and re-coarctation. Cardiovasc Surg. 1995;3:573-8.

16. Bacha E, Almodovar M, Wessel DL, Zurakowski D, Mayer JE, Jonas RA, et al. Surgery for coarctation of the aorta in infants weighing less than 2 kg. Ann Thorac Surg. 2001;71:1260-4.

17. Reddy VM, McElhinney DB, Sagrado T, Parry AJ, Teitel DF, Hanley FL. Results of 102 cases of complete repair of congenital heart defects in patients weighing 700 to 2500 grams. J Thorac Cardiovasc Surg. 1999;117:324-31.

18. Weinstein S, Gaynor JW, Bridges ND, Wernovsky G, Montenegro LM, Godinez RI, et al. Early survival of infants weighing 2.5 kilograms or less undergoing first-stage reconstruction for hypoplastic left heart syndrome. Circulation. 1999;100(Suppl):II-167-70.

19. Pfammatter JP, Ziemer G, Kaulitz R, Heinemann MK, Luhmer I, Kallfelz HC. Isolated aortic coarctation in neonates and infants: results of resection and end-to-end anastomosis. Ann Thorac Surg. 1996;62:778-83. 